results were based on bacteriological investigations. The nearest approach to it is in a series published by Eichorst where he got positive results in 15 out of 23 cases by inoculating guinea-pigs with the aspirated serum. It is, however, nearly identical with the results obtained in a series of 15 cases quoted by Netter, where 13 reacted to the tuberculin test. Combining the latter with the 10 cases here reported a total of 25 is given, of which 22 showed a positive reaction. But if tuberculin is the delicate reagent which it is claimed to be, and which there is good reason to suppose it really is, these figures cannot be accepted as an absolute criterion of the proportion of idiopathic pleurisies in which the tubercle bacillus is the etiological factor, since the possibility cannot be eliminated that they might be due to a coincident infection with some other organism of patients with a latent tubercular focus in some other portion of the economy, to which the reaction was due, and which would be a source of error whose importance could not be estimated.

Before closing a word should be said as to the repopted dangers arising from the use of tuberculin as a diagnostic agent, about which much has been written. My experience in its administration for such purposes is limited to about 40 cases; but so far as it goes it shows that none is to be apprehended when it is given in doses only large enough to lead to an elevation of temperature. Such a dose rarely needs to exceed one milligramme, and frequently less than that quantity is sufficient.

\section{THE DIAGNOSTIC VALUE OF TUBERCULIN.*}

BY FRANKLIN W. WHITE, S.B. M.D., BOSTON.

During the past year, at the suggestion of Dr. F. C. Shattuck, a series of observations were made at the Massachusetts General Hospital to determine the diagnostic value of tuberculin injections. The injections were given to 123 ward patients, all adults, with the exception of one child of two years; 93 of these cases I report from personal observation; the results of 30 subsequent injections made by Dr. J. A. Capps are reported from the hospital records.

In selecting cases for injection, only those patients who were afebrile, or nearly so, and whose physical condition was fairly constant from day to day, were considered suitable.

In addition to the usual daily chart of the patient's morning and evening temperature, a four-hourly chart was kept, beginning at least twenty-four hours before the injection and continuing for several days after it. The injections were made with an ordinary hypodermic syringe, which was sterilized each time before using, by boiling the needle, and filling the syringe with 95 per cent. alcohol. The solutions used were 1 to 1000,1 to 500 and 1 to 100 dilutions of Koch's tuberculin in distilled water, the solutions being made up freshly every day or two.

The injection was made, as a rule, deep into the muscles of the back or thigh. In 18 cases the injection was made subcutaneously in the arm, in some of which a local inflammation occurred which completely disappeared in a few days. The deep injection

* Read at a meeting of the Clinical Section of the Suffolk District Medical Society, March 17, 1897. is preferable, never producing any local phenomena beyond a slight stiffuess in tho muscles the day after injection, in about one-lialf the cases.

The doses of tuberculin given were one, two, five, seven, and ten milligrammes, obtained by giviug one-hulf to one cubic centinetre of the above-named dilutione. At first, to avoid any possibility of an overdose, an injection of one or two milligrammes was given; and if this produced no reaction, it was followed in two or three days by an injection of 10 milligrammes. In a few cases, an initial injection of five or seven milligrammes was given. After treating about 35 cases in this way, it was found that the one and two milligramme doses could not be relied on to produce a reaction in tuberculous cases, and that the ten-milligramme doses had given no bad results; so the small, preliminary doses were omitted in the remaining cases.

Three tuberculous cases, which were given doses of five milligrammes, reacted promptly. As a rule, ten milligrammes of tuberculin were given at one dose for the sake of uniformity and to avoid the remarkable "tolerana" which is speedily established by the use of small repeated doses, and because it was believed that a dose of ten milligrammes would give a more definite characteristic reaction, both as regards temperature and constitutional disturbance, than a single dose, onethird or one-half as large.

There is much diversity of opiuion about the size of dose which is most desirable in diagnostic work. Koch ${ }^{1}$ says in his early articles that the smallest quantity requisite to produce an effect in healthy individuals is about ten milligrammes, that phthisical cases are more susceptible than surgical cases, and react to one or two milligrammes, and that tuberculous childreu react to one-half or one milligramne. Berthenson ${ }^{2}$ states that one milligramme usually produces a fair reaction in tuberculous adults. Grasset ${ }^{8}$ used two-tenths or three-tenths for a first dose and if no reaction followed, five-tenths of a milligramme for a second dose, and belives that these small doses are useful in diagnosticating early cases. There is, however, one serious objection to 8 mall repeated doses. Grasset, Neisser and Von Ruck ${ }^{5}$ admit that the patients may become habituated to them, and cite a uumber of cases of phthisis treated in this way without reaction.

Von Jaksch ${ }^{6}$ says ten milligrammes is too large a dose for diagnostic purposes, that five milligrammes is better. Speaking of children, Gaffie ${ }^{7}$ advises the use of a dose of one-twentieth of a milligramme. Kossel ${ }^{10}$ used two-tenths to one milligramme as a first dose, and if no reaction occurred, gave five or ten milligrammes two days later. As the temperature of children is very variable and easily affected by slight causes, he recommends a repetition of the dose causing reaction in all cases to be sure the temperature was due to the tuberculin.

'The discrepancy in the size of the dose advised by different men may, perhaps, be partly explained by possible variation in the strength of different samples of tuberculin. There are, apparently, a number of conditions apart from the amount of tubercular process present upon which the febrile reaction depends, such as :

(1) Individual disposition.

(2) Size of dose.

(3) Habituation of the patient to tuberculin. 
(4) Sex. Ruedi ${ }^{8}$ asserts that females react less readily than males. Our results do not confirm this statement.

(5) Time of injection. Rosenbach ${ }^{9}$ says that the febrile reaction after an injection in the morning is more prompt, higher and shorter than after one in the afterwoon. In our cases, almost all the injections are made about $8 \mathrm{P}$. M. for convenience, and the reactions are of the type Rosenbach describes as "late reactions," slow in onset and long in duration, the temperature rising about eight and one-half hours after injection, and falling to normal after about twentynine hours. Compare this with Koch's description of a "typical reaction" with a temperature rising four or five hours after injection and lasting from twelve to fifteen hours.

There have been no bad results from our injections, the worst being a condition resembling a "touch of grippe," usually lasting a little over twenty-four hours in the reacting cases. No definite changes in local tubercular processes were, as a rule, discovered after the single injection. In classifying the cases, we arbitrarily define a "reaction" following injection as a condition of fever of $101^{\circ}$ or over, associated with the ordinary febrile symptoms, general malaise, headache, anorexia, pain in the back, etc. In giving the injections to patients whose temperature and general condition was tolerably stable, the "reacting" patients were very readily distinguished from the "nonreacting " by the abrupt rise of temperature and constitutional disturbance following several hours after injection.

One hundred and twenty-three patients were injected with tuberculin, 45 of whom were tuberculous, 8 of whom were classed as "doubtful " and 70 of whom gave no clinical evidence of tuberculosis.

Reactions were obtained in 66 cases (see tables).

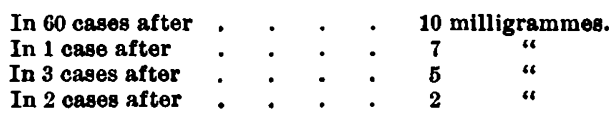

The temperature began to rise eight and fourtenths hours after injection.

The averages of the reactions in 66 cases are as follows :

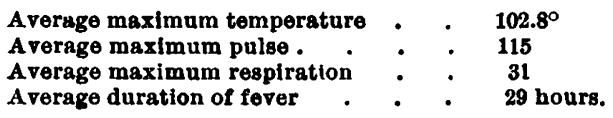

The following figures give the limits of variation in the reactions :

Longest period after injection before rise of temperature 24 hours. Shortest period after injection . . . . . . 1 hour. Higheat maximum ferer.

Lowest maximum fever

Highest maximum pulso .

Lowest maximum pulge.

Highest maximum respiration

Jowest maximum respiration

Greatest duration of fever

$106.2^{\circ}$

- $106.2^{\circ}$

- 160

88

60

20

84 hours.

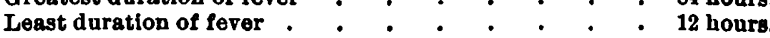

On arranging results by sexes, we find that 68 males were injected, 36 cases or 53 per cent. reacted, with an average maximum temperature of $102.7^{\circ}$, and an average maximum pulse of $108 ; 55$ females were injected, 30 cases or 54 per cent. reacted, with an average maximum temperature of $103^{\circ}$ and an average maximum pulse of 123 .

Now, considering the reacting cases in detail, we find that a well-marked reaction was obtained in 29 cases where excellent evilence of tuberculosis was present, comprising:

Ten cases of phthisis with tubercle bacilli in sputa. Eleven cases of bone and joint tubercle.

One case of skin and two of glandular tuberculosis. Five cases of tubercular peritonitis.

\begin{tabular}{|c|c|c|c|c|c|c|c|c|}
\hline 号 & l)iagnosis. & 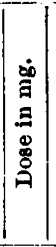 & 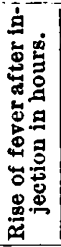 & 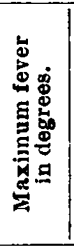 & 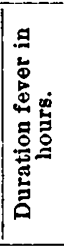 & 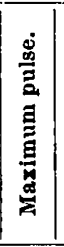 & 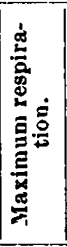 & 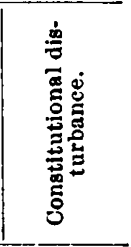 \\
\hline $\begin{array}{c}1 \\
2 \\
3 \\
4 \\
5 \\
6 \\
7 \\
8 \\
9 \\
10 \\
11 \\
12 \\
13 \\
14 \\
15 \\
16 \\
17 \\
18 \\
19 \\
20 \\
21 \\
22 \\
23 \\
24 \\
25 \\
26 \\
27 \\
28 \\
29 \\
30 \\
31 \\
32 \\
33 \\
34 \\
35 \\
36 \\
37 \\
38\end{array}$ & 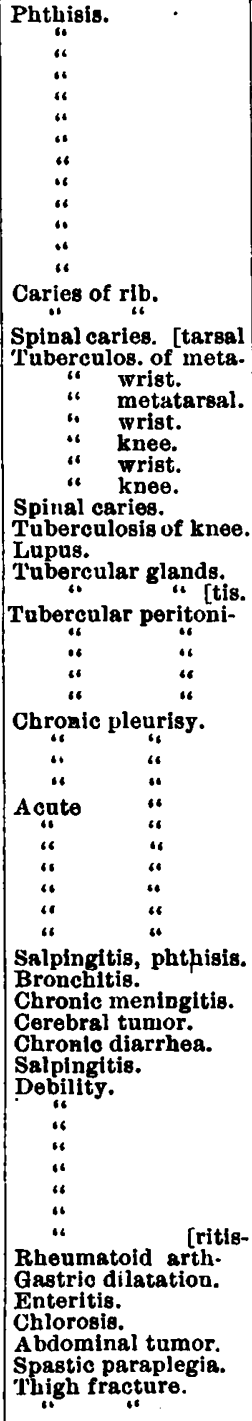 & $\begin{array}{r}10 \\
10 \\
10 \\
10 \\
10 \\
10 \\
10 \\
5 \\
5 \\
10 \\
10 \\
10 \\
10 \\
10 \\
10 \\
10 \\
10 \\
10 \\
10 \\
10 \\
10 \\
10 \\
10 \\
10 \\
10 \\
10 \\
10 \\
10 \\
10 \\
10 \\
10 \\
10 \\
10 \\
10 \\
10 \\
10 \\
10 \\
10 \\
10 \\
10 \\
10 \\
10 \\
5 \\
70 \\
10 \\
10 \\
10 \\
10 \\
10 \\
10 \\
10 \\
10 \\
10 \\
10 \\
10 \\
10 \\
10 \\
10 \\
10 \\
10 \\
10 \\
10 \\
10 \\
10 \\
2 \\
10\end{array}$ & $\begin{array}{r}5 \\
5 \\
8 \\
8 \\
4 \\
4 \\
4 \\
8 \\
8 \\
4 \\
5 \\
5 \\
4 \\
12 \\
4 \\
6 \\
12 \\
12 \\
6 \\
10 \\
8 \\
8 \\
5 \\
7 \\
12 \\
12 \\
24 \\
16 \\
8 \\
4 \\
8 \\
3 \\
4 \\
8 \\
4 \\
7 \\
12 \\
12 \\
5 \\
5 \\
5 \\
16 \\
12 \\
8 \\
8 \\
5 \\
8 \\
4 \\
8 \\
12 \\
15 \\
10 \\
8 \\
12 \\
12 \\
8 \\
12 \\
12 \\
2 \\
8 \\
1 \\
12 \\
8 \\
20 \\
16 \\
9\end{array}$ & $\begin{array}{l}101 . \\
102 . \\
103 . \\
103.3 \\
102.7 \\
103.3 \\
101.8 \\
104.8 \\
101.8 \\
106.2 \\
102 . \\
101.8 \\
102.6 \\
102.2 \\
103.4 \\
104 . . \\
101.9 \\
105 . \\
102 . \\
102.3 \\
101.8 \\
101 . \\
102.3 \\
102.6 \\
102.4 \\
103.8 \\
101.2 \\
101.2 \\
105 . \\
103.2 \\
104.8 \\
105 . \\
103.4 \\
104 . \\
104.2 \\
101 . \\
101.8 \\
102.8 \\
104.8 \\
104.8 \\
104.5 \\
103 . \\
102.2 \\
103.3 \\
102.4 \\
103 . \\
102.5 \\
102.5 \\
102.5 \\
102 . \\
102.3 \\
102 . \\
103 . \\
102 . \\
101.4 \\
103.5 \\
104 . \\
103.7 \\
101.7 \\
102 . \\
103.8 \\
101.4 \\
102.8 \\
103.2 \\
102 . \\
102.5 \\
\end{array}$ & $\begin{array}{l}16 \\
14 \\
28 \\
28 \\
24 \\
36 \\
12 \\
36 \\
24 \\
36 \\
32 \\
24 \\
20 \\
24 \\
34 \\
38 \\
20 \\
36 \\
24 \\
16 \\
28 \\
24 \\
24 \\
20 \\
36 \\
60 \\
36 \\
32 \\
24 \\
32 \\
20 \\
36 \\
24 \\
28 \\
24 \\
24 \\
60 \\
20 \\
32 \\
32 \\
28 \\
24 \\
20 \\
24 \\
24 \\
18 \\
38 \\
24 \\
20 \\
20 \\
36 \\
32 \\
44 \\
24 \\
20 \\
24 \\
40 \\
68 \\
56 \\
24 \\
84 \\
16 \\
36 \\
48 \\
20 \\
24\end{array}$ & \begin{tabular}{|r|}
120 \\
105 \\
112 \\
120 \\
123 \\
100 \\
80 \\
120 \\
104 \\
145 \\
96 \\
80 \\
120 \\
120 \\
100 \\
140 \\
120 \\
100 \\
140 \\
88 \\
90 \\
92 \\
120 \\
120 \\
108 \\
102 \\
110 \\
103 \\
127 \\
160 \\
104 \\
112 \\
108 \\
120 \\
110 \\
116 \\
108 \\
100 \\
130 \\
130 \\
120 \\
108 \\
140 \\
100 \\
119 \\
120 \\
132 \\
147 \\
90 \\
100 \\
100 \\
105 \\
117 \\
80 \\
88 \\
113 \\
104 \\
110 \\
140 \\
80 \\
132 \\
80 \\
130 \\
108 \\
110 \\
98 \\
\end{tabular} & $\begin{array}{l}31 \\
29 \\
32 \\
38 \\
33 \\
29 \\
25 \\
33 \\
30 \\
40 \\
25 \\
28 \\
\ddot{44} \\
29 \\
60 \\
35 \\
\ddot{0} \\
\ddot{25} \\
20 \\
24 \\
20 \\
31 \\
\ddot{.0} \\
\ddot{25} \\
36 \\
45 \\
\ddot{37} \\
28 \\
31 \\
33 \\
30 \\
24 \\
26 \\
51 \\
36 \\
36 \\
29 \\
32 \\
31 \\
32 \\
29 \\
\ddot{30} \\
25 \\
24 \\
24 \\
22 \\
35 \\
23 \\
22 \\
21 \\
32 \\
30 \\
\ddot{24} \\
32 \\
28 \\
28 \\
32 \\
29 \\
31\end{array}$ & 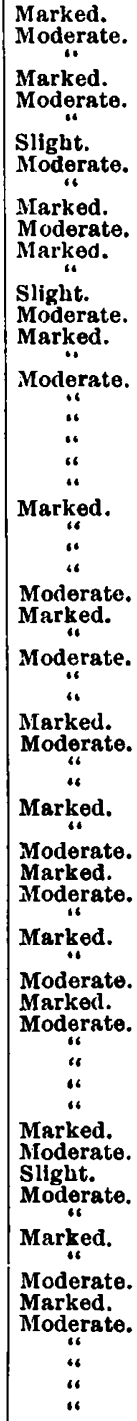 \\
\hline
\end{tabular}

Also, in 16 cases where the presumptive evidence of tuberculosis was very strong, comprising :

Three cases with a clinical diagnosis of phthisis, but without tubercle bacilli in sputa : one of these with a family history of phthisis, crackles and dulness at apex, sweats, loss of weight; one with pulmonary hemorrhages and signs at apex; one with cough and signs at apex, in bed seven months.

Four cases of chronic pleurisy : one with cough for 
two years, sweats and loss of weight; one with loss of weight and crackles at apex.

Seven cases of acute pleurisy: one with bloody Huid and crackles at apex; ono with a tuberculous knee eighteen years previous; one with a family history of phthisis; one with loss of weight and previous cough.

One case of salpingitis, with tubercular family history, signs at apex and loss of 40 pounds weight.

One spunal caries, with lumbur antero-posterior curvature with pain and tenderness.

Forty-five cases in all.

Reactions were obtained in a considerable number of cases where absolute evidence of tuberculosis was not obtainable, in one each of bronchitis, chronic meningitis, cerebral tumor, chronic diarrhea, salping1tis, rheumatoid arthritis, gastric dilatation, enteritis, chlorosis, abdominal tumor and spastic paraplegia; in two cases of thigh fracture and in eight cases of debility; 21 cases in all. Fight of these cases we class as "doubtful," as each may be fairly suspected of tuberculosis, but none give absolute evidence. We have drawn no conclusions as to the diagnostic value of the method from these cases. They comprise. four cases of debility (two with tuberculous family history, one with cough for six months, one with cough for four months, sweats, loss of flesh, and having a tuberculous wife and child), also one case of salpingitis, one chronic meningitis, one chronic diarrhea, and one cerebral tumor.

The remaining 17 cases have nothing indicating tuberculosis in family or personal history (except debility and the loss of flesh) or on physical examination.

Adding these 13 cases to the 57 non-reacting cases, we find that of 70 patients giving no clinical evidence of tuberculosis, 18.5 per cent. reacted. It is fair to assume from these facts that tuberculin will cause a reaction in some non-tuberculous cases; and, on the other hand, this class of cases would probably be much smaller in our lists if we were able to rule out all cases of possible glaudular or incipient pulmonary tuberculosis in which the reaction to tuberculin is the only evidence we have of the presence of the bacillus. To illustrate the small value of clinical evidence of some cases, we quote the following series: Kossell, ${ }^{10}$ speaking of 28 reacting cases among children of one to ten years of age, in only four of which clinical evidence of tuberculosis was present, says that in accordance with his experience at autopsies in such children, at least two-thirds of the remaining 24 cases are to be considered as tuberculosis of the bronchial or mesenteric glands.

Many writers report cases of reaction in the socalled non-tuberculous, some after small doses. For example, Kohler and Westphal ${ }^{11}$, Leyden ${ }^{12}$, Peiper ${ }^{18}$, Auerbach ${ }^{14}$, Post ${ }^{16}$, and Maydl ${ }^{16}$ report collectively over 30 cases reacting to doses of one, two, three and five milligrammes, and a number of other cases reacting to larger doses.

Granting that these cases reacting to doses of tuberculin as small as one or two milligrammes were really non-tuberculous, it is evident that we cau hardly expect to ever make the injection test an absolute one; even when we have determined the smallest reliable dose for tubercular cases, we shall probably find occasional non-tuberculous individuals who will react to it.
In 57 cases $†$ tuberculin was injected without reaction. In most of these cases the injection was mule simply to test the method upon the non-tuberculous. In a considerable number of them it proved neeful in making a diagnosis, which was confirmed by operation, or by the subsequent history of the case. 'There is no evidence of tuberculosis in a single non-reacting case.

As instances of its use in diagnosis, we cite the following non-reacting cases:

$\Lambda$ case of supposed tuberculosis of the mesenteric glands failed to react; an operation proved it to be retro-peritoneal sarcoma.

A case of ascites, supposed to be tubercular peritonitis, failed to react; an operation showed no trace of tuberculosis in the abdomen.

A case of supposed hip-disease, with pain and stiffness, failed to react; subsequent history showed it to be an hysterical hip.

A case of marked general debility and anemia failed to react; blood examination showed it to be a progres. sive pernicious anemia.

Four cases of bronchitis failed to react; the lungs cleared up and the patients were discharged well.

Nine cases of general debility failed to react; all the patients were later discharged well.

It is interesting to note, in connection with the possible tubercular origin of acute serous pleurisy, that seven out of the eight of these cases rescted; four chronic pleurisies also reacted. In two of these reacting cases (one acute, one chronic) there were sigus of incipient disease at one apex.

In looking over our results, we see that a wellmarked reaction was obtained in every case where evidence of tuberculosis was present, and in a little less than one-fifth of the patients in whom no evidence of tuberculosis was obtainable.

We might infer from these results that the presence of a reaction after tuberculin indicates the presence of a tubercular process about four times out of five, and that the absence of a reaction indicates an abseuce of auy tubercular process in the patient injected. We cannot, however, insist on this last statement in view of the results of other observers. All our cases of tuberculosis have reacted; whether this was due to the method of giving a single good-sized dose of tuberculin or to the limited number of the cases, or to the fact that very few were advanced cases, it is impossible to say. Previous writers have reported occasional rare and usually advauced cases of undoubted tuberculosis without reaction.

Berthenson ${ }^{2}$ reports two cases, aud Heron ${ }^{17}$ one advauced case of tuberculosis, with a fall of temperature after each iujection. Ruedi ${ }^{8}$ reports an advanced case where constitutioual aud local reaction were present without any febrile reaction. Braun ${ }^{18}$ reports one advanced case. Post gives ${ }^{15}$ one advanced case, and Bobrick ${ }^{10}$ two advanced cases of tuberculosis without general reaction. Neisser says that old lung cases may react only locally.

In our experiments the general febrile reaction has been chiefly studied and regarded as the most reliable diagnostic phenomenon; and on this basis, the tuberculin injection for diagnosis is of least value in ad-

† 'l'hese patients consist of cases of debllity, rhoumatism, nouralgin, anemia, convalesconts from acute infectlous disenses, I ractures, bronchitis, serous pleurisy (one acute case), choren, gustric ulcer. caucer of stomach and liver, asciten, pregnancy, salpingitio (gonor. rheal), pyelitis, laryngitis, nephritis and gall-stones. 
vanced cases, where, as is well known, the general reaction is slight and the local reaction marked, and is most sure where it is at the same time most useful. nawely, in early. cases which give a marked general and slight local reaction.

The difficulty or impossibility of observing the local reaction in many cases, especially the early oues, renders it of little value as a diagnostic point.

Objections bave been raised to the use of tuberculin, even for diagnostic purposes, on the ground that there may be danger of poisoning the patient, or of stirring up latent tubercle bacilli and offering them a better opportunity for growth. We can only say that the method of diagnosis in our hands has been productive of no ill results, as far as we know, beyoud a day's discomfort to the patient, and that the occasional dangers of continued tuberculin treatment of tuberculosis in general, including advanced cases, have not been met with in using a single dose of tuberculin for diagnosis in incipient cases. When we see the brilliaut results obtained in the diagnosis of tuberculosis in cattle by this method, a correct diagnosis in over 99 per cent. of the cases, it seems as if a further experience in the observation of the reactions and a better knowledge of the most desirable dose were all that were necessary to make this a diagnostic method of the greatest value for man. It was a great advance when Koch gave us the method for fiuding the bacillus of tuberculosis, but before the diagnosis can be made by the microscope, it can usually be made without it. When we find the bacilli, our diagnosis is certain; but failure to find them does not exclude the disease. The tuberculin test is much more helpful in early diagnosis. An injection will show the presence of the bacilli long before the inflammatory process is apparent to sight or touch; and on the other band, a negative result gives absolute surety of freedom from tuberculosis, which of itself is often of the greatest value.

We will summarize briefly as tollows :

(1) The tuberculin method is simple and easily applied. An absence of reaction after injection indicates almost invariably an absence of tuberculosis. The presence of a reaction indicates the presence of tuberculosis more than four times out of five.

(2) The method is especially applicable to the diagnosis of incipieut pulwouary tuberculosis aud of glandular, peritoueal, pleural aud bone tuberculosis, where the bacilli cannot readily be found.

(3) The general febrile reaction is a more generally useful diagnostic phenomenon than the local reaction.

(4) 'The use of small preliwinary doses of tuberculin is to be avoided on the ground of producing a gradual tolerance and a loss of general reaction.

(5) 'Ihe size of the best dose for diagnostic work is a matter for further study. It is probably between five and ten milligrammes for adults.

(6) Rued's statement, that females react to tuberculin less readily than males, has not been confirmed by our results.

\section{BIBLIOGRAPHY}

1. Koch. Deutsche med. Woch., xvi, 1890, p. $102 \mathrm{~J}$.

2. Berthenson. Loc. cit., xviii, 1892, p. 53.

3. Grasset. Bull. A cad. de Médecine, Paris, 3 S., xxxv, 1896 , p. 174.

4. Neisser. Deutsche med. Woch., xviii, 1891, p. 205.

5. Von Ruck. Times and Register, xxii, 1891, p. 209.

6 . Von Jaksch. Verhandl. d. Congress f. innere. med., Wiesbaden, $X, 1891$, p. 87.

7. Gaffie. Thèse de Paris, 1895.
8. Ruedi. The Practitioner, xiii, 1892, p. 171.

9. Rosenbach. Deutsche med. Woch., xvii, j891, p. 77

10. Kossel. Zeitsch. f. Hyg. u. Infectkranklieit., Bd. xxi, p. 59,

11. Kohler and Westphal. Deutsche med. Woch., xvi, 1890, p. 1058.

12. Leyden. Berlin klin. Woch., xxviii, 1890, p. 1145.

13. Peiper. Dentsche med. Woch., xvii, 1891, p. 160.

14. Auerbach. Loc. cit., $x$ vii, 1891, p. 246 .

15. Post. Müuchener med. Woch, 1891, p. 701.

16. Maydl. Interuat. klin., Rundschau., 1890, No. 50.

17. Heron. lancet, i, 1891, p. 920 .

18. Braun. Deutsche med. Woch., xvii, 1891, p. 412.

19. Bobrick. Loc. cit., $x$ vii, 1891 , p. 381.

\section{SOME CASES OF CYSTITIS IN WOMEN. ${ }^{1}$}

BY EDGAR GARCEAU, M.D.,

Surgeon to Out-patients, Free Hospital for Women, Boston; Clinical Instructor in Gynecology in Tufts Medical School.

(Concluded from No. 5, p. 100.)

Case V. Acute nodular cystitis, purulent eudometritis, fistula in ano, patulous meatus. Symptomatic cure in two weeks. Persistence of vesical lesions notwithstanding symptomatic cure.

Mrs. D. was a woman, forty years old, who had had three children and six miscarriages. She gave a history of ischio-rectal abseess, which left a fistula. Three weeks before examination she was attacked by frequent painful micturition, which compelled her to seek advice.

On examination the fistula was observed, and also a purulent discharge, which proceeded from the uterine cavity and bathed the meatus with pus. The pus had no difficulty in finding ready access to the bladder through a meatus which was markedly patulous. Cystoscopic examination showed a bladder which was greatly inflamed. The urethra, vesical neck, trigonum, and ureteral eminences were much injected, and on the eminences were several small yellow points. The blood-vessels of the bladder were all injected, and scattered about here and there were many nodules of hperemic appearance. The whole wall was cloudy looking. The infection bad evidently proceeded from the purulent endometritis. The treatment was, for a month, nothing but a mixture of equal parts of fluid extract of buchu and tincture of benzoin compound taken internally. Under this she improved so that at the end of a week from the time of beginuing treatment she was completely cured symptomatically, and was urinating only three times a day aud not at all at night.

In order to be sure that the bladder was normal, in view of the rapid cure taken in connection with the severe inflammation, another examination, a month after beginning treatment, was made, with the result that the appearances were found to be exactly the same as at the first examination. She then had injections of permanganate of potash solution; and these were continued for a period of two months, when another examination was made. The appearances had altered but little. There was perhaps a slight diminution in the degree of iujection, but the nodules remained and the cloudy appearauce as well. It looked like a severe case of cystitis. But on examining urine obtained with the catheter, it was found to be free from pus, in this respect differing from the urine at the outset of the disease. No more treatment is now being given, except that directed to the purulent endometritis. In order

1 Read before the Gynecological Section of the Massachusetts Medical Society, February 24, 1897. 